\title{
Safety of Transrectal or Transvaginal Drainage of Pelvic Abscesses
}

\section{Segurança da drenagem transretal ou transvaginal de abscessos pélvicos}

\author{
Mohammed lyoob Mohammed Ilyas ${ }^{1}{ }^{(1)}$ Pridvi Kandagatla $^{2}{\text { Craig A. } \text { Reickert }^{2} \text { Surya Nalamati }}^{2}$ \\ Shawn P. Webb ${ }^{2}$ Eric J. Szilagy ${ }^{2}$ Amalia J. Stefanou ${ }^{20}$
}

${ }^{1}$ HSHS Medical Group, Springfield, IL, United States.

2 Henry Ford Health System, Wayne State University, Detroit, MI, United States.

J Coloproctol 2021;41(1):47-51.
Address for correspondence Mohammed lyoob Mohammed Ilyas, MD, MS, MRCS, FACS, FASCRS, Department of Surgery, Eisenhower Health, 39000 Bob Hope Drive, Rancho Mirage, California, USA, 92270 (e-mail: mriyoob@gmail.com).

\begin{abstract}
Keywords

- transrectal

- transvaginal

- pelvic abscess

- interventional drainage
\end{abstract}

\section{Resumo}

Objective The literature on the safety and long-term sequelae of transrectal and transvaginal drainage of pelvic abscesses is limited. We evaluated the outcomes and safety of pelvic abscess drainage by interventional radiology at our institution.

Methods After obtaining institutional review board approval, we retrospectively evaluated the outcomes of transrectal and transvaginal pelvic abscesses drainage using computed tomography, endorectal ultrasound, and or fluoroscopy.

Results The study included 26 patients, with an age range of 24 to 88 years old, out of whom $53.8 \%$ were men. A total of $46.1 \%$ of the participants were African Americans and 26.9\% were Caucasians. The average body mass index was 28.4 (range: 15.6 to 41.9 ). The most common etiology was penetrating abdominal injury (27\%), followed by appendectomy (23\%), diverticular disease (11.5\%), anastomotic leak (11.5\%), and disorders of gynecological causes (11.5\%). The mean abscess diameter was $6.3 \mathrm{~cm}$ (range: 3.3 to $10.0 \mathrm{~cm}$ ). Transrectal drainage was performed in all except one patient who had a transvaginal drainage. Transrectal ultrasound was used for drainage in $92.3 \%$ cases, and fluoroscopy was used as an additional imaging modality in $75 \%$ of the cases. An 8 - or 10 -Fr pigtail catheter was used in $>80 \%$ of the patients. Drains were removed between 2 and 7 days in $92.3 \%$ of the cases. The average follow-up was 30.4 months (range: 1 to 107 months), and no long-term complications were reported. Only one patient required subsequent operative intervention for an anastomotic leak.

Conclusions Pelvic abscess drainage by transrectal route using radiological guidance is a safe and effective procedure.

Objetivo A literatura sobre a segurança e as sequelas no longo prazo da drenagem transretal e transvaginal do abscesso pélvico é limitada. Avaliamos os resultados e a received

July 4, 2020

accepted

August 23, 2020
DOI https://doi.org/

10.1055/s-0041-1724059. ISSN 2237-9363. (c) 2021. Sociedade Brasileira de Coloproctologia. All rights reserved.

This is an open access article published by Thieme under the terms of the Creative Commons Attribution-NonDerivative-NonCommercial-License, permitting copying and reproduction so long as the original work is given appropriate credit. Contents may not be used for commercial purposes, or adapted, remixed, transformed or built upon. (https://creativecommons.org/ licenses/by-nc-nd/4.0/)

Thieme Revinter Publicações Ltda., Rua do Matoso 170, Rio de Janeiro, RJ, CEP 20270-135, Brazil 


\section{Palavras-chave \\ - transretal \\ - transvaginal \\ - abcesso pélvico \\ - drenagem intervencionista}

\begin{abstract}
segurança da drenagem do abscesso pélvico por radiologia intervencionista em nossa instituição.

Métodos Após obter a aprovação do conselho de revisão institucional, avaliamos retrospectivamente os resultados da drenagem de abscessos pélvicos transretais e transvaginais por meio de tomografia computadorizada, ultrassom endorretal, e/ou fluoroscopia.

Resultados Participaram do estudo 26 pacientes, com faixa etária de 24 a 88 anos, dos quais $53,8 \%$ eram homens. Um total de $46,1 \%$ eram afro-descendentes, e $26,9 \%$ eram brancos. $O$ índice de massa corporal médio foi de 28,4 (gama: 15,6 a 41,9). A etiologia mais comum foi lesão abdominal penetrante (27\%), seguida de apendicectomia (23\%), doença diverticular (11,5\%), fístula anastomótica $(11,5 \%)$ e distúrbios de causas ginecológicas (11,5\%). O diâmetro médio do abscesso foi de $6,3 \mathrm{~cm}$ (gama: 3,3 a $10,0 \mathrm{~cm}$ ). A drenagem transretal foi realizada em todos os pacientes, com exceção de uma, que foi submetida a uma drenagem transvaginal. A ultrassonografia transretal foi utilizada para drenagem em $92,3 \%$ dos casos, e a fluoroscopia como modalidade adicional de imagem, em 75\% dos casos. Um catéter duplo J de 8 ou $10 \mathrm{Fr}$ foi usado em $>80 \%$ dos pacientes. Os drenos foram retirados entre 2 e 7 dias em 92,3\% dos casos. O acompanhamento médio foi de 30,4 meses (gama: 1 a 107 meses), e nenhuma complicação de longo prazo foi relatada. Apenas um paciente necessitou de intervenção cirúrgica subsequente para um vazamento anastomótico.

Conclusão A drenagem do abscesso pélvico por via transretal com orientação radiológica é um procedimento seguro e eficaz.
\end{abstract}

\section{Introduction}

Historically, pelvic abscesses were drained using surgical drainage. But, with advances interventional radiology techniques, percutaneous drainage has now become the preferred treatment modality for intra-abdominal and pelvic abscesses. This may also help avoid surgery to drainage such surgery. ${ }^{2}$ Percutaneous drainage has now become the preferred treatment modality for intra-abdominal and pelvic abscesses, as this method is shown to have a reduced morbidity and mortality when compared with surgical drainage and may also help to avoid surgery. ${ }^{2}$ Percutaneous drainage is usually done with the aid of imaging techniques, such as computed tomography (CT) or ultrasound (US). ${ }^{4,5}$ Often, dynamic imaging, such as fluoroscopy, is also used to facilitate the technique.

Percutaneous drainage techniques, however, may be limited and are not always the appropriate option for drainage of pelvic abscesses. In individual patients, the proximity of the collection to adjacent vital structures may prevent a safe path for the guiding needle, wire, or catheter. ${ }^{6}$ In these patients, surgical drainage would be the alternative approach. Recently, however, more difficult to access abscesses are being targeted with the use of endoluminal techniques. Endoscopic ultrasound (EUS) is now being utilized to guide the drainage of abscesses that are difficult to access with the traditional percutaneous drainage methods. ${ }^{7}$ Deep pelvic abscesses may benefit from endoscopic drainage, specifically transrectal or transvaginal drainage. ${ }^{4,8}$ There are, however, limited studies describing the outcomes of transrectal or transvaginal drainage in a larger sample of patients.

The objective of the present study is to review our experience with patients that have undergone transrectal or transvaginal drainage of intra-abdominal abscesses and to analyze the outcomes of the procedure among these patients. By doing so, we hope to describe the safety and efficacy of transrectal or transvaginal drainage as a modality for draining pelvic abscesses not accessible by percutaneous approach.

\section{Methods/Interventions}

After obtaining institutional review board approval, we reviewed the electronic medical charts from two regional hospitals belonging to single health care system for patients who underwent interventional drainage for a pelvic abscess from 2005 to 2016. The included patients were above 18 years of age and underwent drainage of pelvic abscesses by transrectal or transvaginal route only. We included patients who had abscess drainage with the guidance of $\mathrm{CT}$, use of endorectal ultrasound (EUS), or with the use of fluoroscopy. The patient demographic data collected include age; gender; ethnicity; medical comorbidities, including coronary artery disease, diabetes mellitus, and congestive heart failure; history of inflammatory bowel disease; body mass index (BMI); and smoking history. A review of all the medications in use by the patient prior to the procedure, including steroids or blood thinners, was also performed. 
The chart was analyzed for specific factors, such as the described etiology of the abscess, preoperative versus postoperative state, and history of prior abscess drainage.

Additional technical details of the procedure, including the route used for drainage (transrectal vs transvaginal), the method of imaging used for the placement of the drainage (CT scan, fluoroscopy or EUS), and the size of the catheter used for drainage, were noted. The type of anesthesia (sedation or general anesthesia), position of patient (lateral, prone or lithotomy), the lengths of hospital stay after placement of drain, postprocedural complications, and need for surgical intervention after placement of the drainage for non-resolution of symptoms were also noted. The time between placement and removal of the drain and resolution of abscess with follow-up imaging, if any, was recorded. The patients' charts were checked for any postprocedural complications, including need for additional drainage procedures and any sequelae, including perianal or rectal fistulae.

\section{Results/Outcomes}

Review of the electronic medical records from the two regional hospitals identified 26 patients who underwent transrectal or transvaginal placement of drain for pelvic abscess. The ages of the patients varied between 24 and 88 (mean age 46.65 , median 40 ), with a near-equal distribution of gender (53.8\% men). African Americans comprised 46.1\% of all patients and $26.9 \%$ were Caucasians. Postoperative pelvic abscess formation after penetrating injury to the abdomen was the etiology for abscess formation in $27 \%$ of the patients, $23 \%$ were after appendectomies, $11.5 \%$ each were related to diverticular disease and gynecological causes. Another $11.5 \%$ of the patients developed an abscess after an anastomotic leak from a low rectal anastomosis. The dimensions of the pelvic abscess ranged from 3.3 to $10.0 \mathrm{~cm}$ in measurement (mean 6.30, median 5.90). All the drainage procedures were performed through the transrectal route, except for one patient who was treated via transvaginal route. Transrectal US probe guidance was used in $92.3 \%$ of cases, and in $75 \%$ of these, such drainage also included fluoroscopic guidance. Computed tomography was used for guiding drainage in $7.6 \%$ of the patients. These procedures were predominantly performed with conscious sedation, except in two patients who had procedures performed in the operating room under general anesthesia with endorectal US guidance. Most of these procedures were performed in the right or left lateral positions and involved placement of a drain, which ranged from 8 to $22 \mathrm{Fr}$ in size, with the majority (80.7\%) being either 8 or $10 \mathrm{Fr}$ in size. The drains were electively removed between 2 and 7 days after their placement, and spontaneous dislodgement occurred in only 2 patients during the postprocedural period.

Follow-up after the procedure ranged from 1 to 107 months (mean 30.4 months, median 18) and included all patients. During the postprocedural follow-up period, one of the patients who had an anastomotic leak from an ileal pouch creation required further drainage procedures in the operating room. None of the patients who had interventional radiology- guided drainage needed follow-up procedures. No evidence of other perianal or perirectal pathologies, including fistulae, were noted in the follow-up period in any patient.

\section{Discussion}

Fluid collections or abscesses deep in the pelvis result from various etiologies and are broadly classified into two main categories, primary and secondary. Primary causes for pelvic abscess include fluid collections resulting from primary disease process like diverticulitis, appendicitis, inflammatory bowel disease, sexually transmitted infections, penetrating abdominal trauma, perforated duodenal ulcer, cholecystitis, and prostatitis. Secondary causes for pelvic abscess include fluid collections resulting from postsurgical complications like after appendectomy, anastomotic leaks post colectomy, post prostatectomy, cystectomy, or ileoanal reservoir formation. Drainage of these fluids are often a challenge to treat because of their location and proximity to organs. ${ }^{8}$ These abscesses, which fail medical management with antibiotics, have been traditionally managed with surgical drainage.

Advanced imaging techniques and the use of stents have helped develop newer techniques in treating deep pelvic abscesses that were not traditionally accessible to interventional drainage. ${ }^{9}$ Transrectal or transvaginal drainage of these abscesses is a feasible option, but is often underused, especially in non-tertiary care centers where expertise in transrectal or transvaginal drainage techniques are limited. ${ }^{10}$ Availability of interventional radiologists familiar with the technique, concern about the effectiveness of the procedure and long-term sequelae from the drainage procedures are likely to be reasons. Multiple studies have demonstrated the effectiveness of the procedure in various studies (6-12). Studies evaluating longterm outcomes and sequelae, if any, from these drainage procedures are limited. The present study was designed to evaluate the effectiveness of the drainage procedure within our institution and long-term sequelae from the drainage procedures, such as formation of perianal or perirectal fistula.

Our study presents short- and long-term outcomes after transrectal or transvaginal drainage of deep pelvic abscesses. The most common etiology for deep pelvic abscesses was exploratory laparotomy after traumatic injuries, such as gunshot wound to the abdomen. Computed tomography scan and US were the most commonly used imaging modalities for evaluation of the abscess. Transrectal or transvaginal drainage of abscess was effective in $96.1 \%$ of patients, thus suggesting its effectiveness as a therapeutic option. The effectiveness of this therapeutic modality is similar to that found in other studies in the literature. The effectiveness of the drainage procedure appears to depend on the etiology of the pelvic abscess. The only case that required an additional surgical drainage procedure was that of a patient who had a pelvic abscess from a postileal pouch anal anastomosis leak. It is important to mention that follow-up of this patient did not find any significant long-term sequelae of these drains.

Deep pelvic abscesses can result from various etiologies, and the most common etiology encountered in our study was postoperative complication. Ramesh et al. describe postsurgical 
abscess as the most common etiology. ${ }^{11}$ Interestingly, the present study found that patients with an etiology of diverticular disease had worse outcomes. Varadarajulu et al. also reported postsurgical complication as the most common etiology of abscesses treated by transrectal drainage (68\%). ${ }^{12} \mathrm{An}$ etiology that was not found in our study was inflammatory bowel disease (IBD). This disease process poses additional challenges, as patients with Crohn's disease are already at a higher risk of fistula formation, and patients with IBD may also be on immunosuppressive medication that could interfere with healing. ${ }^{13,14}$ Other studies had a lower percentage of patients having IBD etiology, but who generally did well despite this diagnosis. ${ }^{11,15,16}$

The transrectal and transvaginal routes of access are only two of many other options, such as transcolonic and ransgluteal. ${ }^{11,17,18}$ The majority of our patients had transrectal drainage, and only one patient had a transvaginal drain, but this route of access is reported in several other studies. A study conducted by Akinci et al. showed that success rates did not significantly differ when comparing the route of access. ${ }^{19}$ Chong et al. also report a 5 -year review showing the clinical success of transvaginal drainage. ${ }^{20}$ The patients reported in this study were from a gynecological center, so all patients had a gynecologic etiology resulting in a deep pelvic abscess. Ho Kim et al. also reported 15 patients that underwent a transvaginal drainage, 14 of whom had a catheter placed. ${ }^{21}$ All of these studies demonstrated a generally high success rate with transvaginal procedures.

Dislodgement of the catheter is always a valid concern after percutaneous drain procedures and may require replacement if the abscess or fluid collection has not been adequately treated. In our study, only one of the patients experienced a dislodgement and did not require further intervention. Lorentzen et al. reported findings of 33 patients that underwent a pelvic abscess drainage and six of the catheters were accidentally dislodged. ${ }^{16}$ However, only one of the dislodged catheters required replacement. Ryan et al. examined 18 patients that underwent drainage of pelvic abscess via a transrectal or transvaginal route. ${ }^{7}$ They found that four of the patients had the drain dislodged, but only one of these patients required a second drain. ${ }^{7}$ Results from our study and the aforementioned studies indicate that though the rate of dislodgement may vary, the need for a catheter replacement is generally low.

The choice of imaging modality varied among the studies. Varadarajulu et al. reported a series of 25 patients that underwent an EUS-guided drain placement for a deep pelvic abscess. ${ }^{12}$ Of these patients, 19 underwent a transrectal drain placement. Ratone et al. also reported findings of transrectal drain placement at a single center involving seven patients. ${ }^{22}$ All of these were done with EUS and there were no complications. Endoscopy, however, may not be available to everyone, especially in treatment settings with limited resources. Ultrasound and CT may also be used as sole imaging modalities for drainage. ${ }^{16,23}$ Our study utilized both endoscopic US and CT as imaging modalities to place the drains, and this provided clinicians with more options for placing the drain. Our providers also performed fluoroscopy to confirm placement of catheters. They reported a $100 \%$ success rate. Similar to these studies, our study also showed success without the need for subsequent operations. In addition, we did not find any longterm sequelae, such as fistulae, in our patients, and our followup period is one of the longest in the current literature.

A strength of our study is the long-term follow-up of our patients. With a median follow-up of 18 months, it allowed us to measure the formation of fistulae and examine other potential long-term consequences of the procedure. Fortunately, none of our patients developed any fistulae or long-term consequences. There are, however, limitations to our study. This is a single institution study, and findings from our study cannot be readily generalized to other institutions. However, our study is one of the largest case series to present the outcomes of this procedure. Furthermore, we show that these drains can be placed with multiple imaging modalities, not just EUS. In addition, the patients involved in this study are diverse in their etiology of abscesses, showing that this treatment modality is greatly worth considering for a wide range of patients. Unfortunately, we only had one transvaginal drain to report, as most of our drains were transrectal. However, this study shows that a transvaginal drain is also an option for deep pelvic abscesses.

This study demonstrates that transrectal or transvaginal drain to treat deep pelvic abscess is associated with low morbidity and low need for subsequent surgical intervention, making it a feasible option in difficult-to-access locations. Many costs and complications can be avoided by using a low-risk procedure such as this. From a patient's perspective, this new option may allow them to undergo treatment while avoiding the costs and possible complications of a surgical procedure. For clinicians, this procedure offers a new tool in the armamentarium to treat patients with deep pelvic abscesses.

\section{Conclusion}

In conclusion, transrectal or transvaginal drains to treat deep pelvic abscesses is a feasible option with low rates of complications. However, large scale prospective studies are needed to fully elucidate the outcomes of this procedure, as well as to define situations in which it is appropriate to utilize this treatment option.

\section{Conflict of Interests}

The authors have no conflict of interests to declare.

\section{References}

1 Solomkin JS, Mazuski JE, Bradley JS, et al. Diagnosis and management of complicated intra-abdominal infection in adults and children: guidelines by the Surgical Infection Society and the Infectious Diseases Society of America. Clin Infect Dis 2010;50(02):133-164

2 Clancy C, Boland T, Deasy J, McNamara D, Burke JP. A Metaanalysis of Percutaneous Drainage Versus Surgery as the Initial Treatment of Crohn's Disease-related Intra-abdominal Abscess. J Crohn's Colitis 2016;10(02):202-208

3 Feingold D, Steele SR, Lee S, et al. Practice parameters for the treatment of sigmoid diverticulitis. Dis Colon Rectum 2014;57 (03):284-294 
4 Charles HW. Abscess drainage. Semin Intervent Radiol 2012;29 (04):325-336

5 Zhao N, Li Q, Cui J, Yang Z, Peng T. CT-guided special approaches of drainage for intraabdominal and pelvic abscesses: One single center's experience and review of literature. Medicine (Baltimore) 2018;97(42):e12905

6 Maher MM, Gervais DA, Kalra MK, et al. The inaccessible or undrainable abscess: how to drain it. Radiographics 2004;24 (03):717-735

7 Ryan RS, McGrath FP, Haslam PJ, Varghese JC, Lee MJ. Ultrasoundguided endocavitary drainage of pelvic abscesses: technique, results and complications. Clin Radiol 2003;58(01):75-79

8 Sudakoff GS, Lundeen SJ, Otterson MF. Transrectal and transvaginal sonographic intervention of infected pelvic fluid collections: a complete approach. Ultrasound Q 2005;21(03):175-185

9 Poincloux L, Caillol F, Allimant C, et al. Long-term outcome of endoscopic ultrasound-guided pelvic abscess drainage: a twocenter series. Endoscopy 2017;49(05):484-490

10 Jaffe TA, Nelson RC, Delong DM, Paulson EK. Practice patterns in percutaneous image-guided intraabdominal abscess drainage: survey of academic and private practice centers. Radiology 2004;233(03):750-756

11 Ramesh J, Bang JY, Trevino J, Varadarajulu S. Comparison of outcomes between endoscopic ultrasound-guided transcolonic and transrectal drainage of abdominopelvic abscesses. J Gastroenterol Hepatol 2013;28(04):620-625

12 Varadarajulu S, Drelichman ER. Effectiveness of EUS in drainage of pelvic abscesses in 25 consecutive patients (with video). Gastrointest Endosc 2009;70(06):1121-1127

13 Xie Y, Zhu W, Li N, Li J. The outcome of initial percutaneous drainage versus surgical drainage for intra-abdominal abscesses in Crohn's disease. Int J Colorectal Dis 2012;27(02):199-206
14 Téoule P, Seyfried S, Joos A, Bussen D, Herold A. Management of retrorectal supralevator abscess-results of a large cohort. Int J Colorectal Dis 2018;33(11):1589-1594

15 Kuligowska E, Keller E, Ferrucci JT. Treatment of pelvic abscesses: value of one-step sonographically guided transrectal needle aspiration and lavage. AJR Am J Roentgenol 1995;164(01):201-206

16 Lorentzen T, Nolsøe C, Skjoldbye B. Ultrasound-guided drainage of deep pelvic abscesses: experience with 33 cases. Ultrasound Med Biol 2011;37(05):723-728

17 Robert B, Chivot C, Fuks D, Gondry-Jouet C, Regimbeau JM, Yzet T. Percutaneous, computed tomography-guided drainage of deep pelvic abscesses via a transgluteal approach: a report on 30 cases and a review of the literature. Abdom Imaging 2013;38(02):285-289

18 Alis H, Soylu A, Dolay K, Aygun E. Endoscopic transcolonic catheter-free pelvic abscess drainage. Can J Gastroenterol 2008; 22(12):983-986

19 Akıncı D, Ergun O, Topel Ç, Çiftçi T, Akhan O. Pelvic abscess drainage: outcome with factors affecting the clinical success. Diagn Interv Radiol 2018;24(03):146-152

20 Chong LY, Toh HW, Ong CL. Transvaginal Drainage of Pelvic Collections: a 5-year Retrospective Review in a Tertiary Gynaecology Centre. Ann Acad Med Singapore 2016;45(01):31-34

21 Ho Kim S, Hyup Kim S, Han H, Soo Kim S, Yeon Lee J, Hwan Jeon Y. Image-guided transvaginal drainage of pelvic abscesses and fluid collection using a modified Seldinger technique. Acta Radiol 2008;49(06):718-723

22 Ratone JP, Bertrand J, Godat S, Bernard JP, Heyries L. Transrectal drainage of pelvic collections: Experience of a single center. Endosc Ultrasound 2016;5(02):108-110

23 Singh N, Negi N, Kumar N. Innovative non-surgical management of pelvic and anterior vaginal wall abscess following vaginal surgery. BMJ Case Rep 2016;2016:bcr2016215341 